$2 /\left.15\right|_{\text {LA-7901-MS }} ^{\circ}$

Informal Report

\section{Preliminary Fabrication Studies of Alternative LMFBR Carbide Fuels}

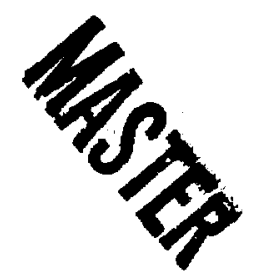

年

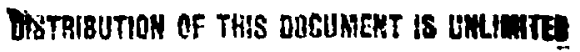


LA-7901-MS

Informal Report

UC-79b (Base Technology)

Issued: October 1979

\title{
Preliminary Fabrication Studies of Alternative LMFBR Carbide Fuels
}

\author{
R. L. Gutierrez \\ R. J. Herbst \\ K. W. R. Johnson
}

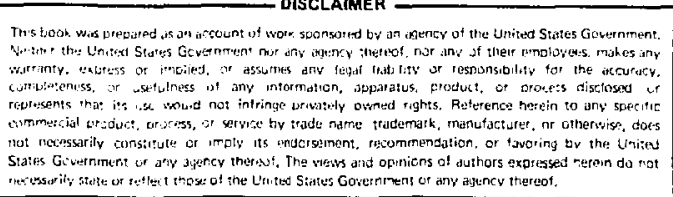




\title{
PRELIMINARY FABRICATION STUDIES OF ALTERNATIVE LMFBR CARBIDE FUELS
}

by

\author{
R. L. Gutierrez, R. J. Herbst, and K. W. R. Johnson
}

\begin{abstract}
Preliminary fabrication studies were made of various compositions of thorium-uranium carbide and thorium-plutonium carbide fuel pellets that were prepared using the carbothermic reduction process. Temperatures of $1750^{\circ} \mathrm{C}$ and $2000^{\circ} \mathrm{C}$ were used during the reduction cycle. Sintering temperatures of $1800^{\circ} \mathrm{C}$ and $2000^{\circ} \mathrm{C}$ were used to prepare fuel pellets of low $(87 \%)$ and high $(>94 \%)$ theoretical densities.
\end{abstract}

\section{INTRODUC'TION}

Thorium-uranium carbide, (Th,U)C, and thorium-plutonium carbide, (Th, $\mathrm{Pu}$ ) C, fuels are being considered as alternative candidates to uraniumplutonium carbide, (U,P:) C, fuel for use in the Advanced Fuels Program for the liquid metal fast breeder reactor (LMFBR). These alternative fuels will minimize the use of plutonium and help serve as a deterrent to the proliferation of plutonium. One deterrent is the production of the ${ }^{232} \mathrm{U}$ isotope from ${ }^{232} \mathrm{Th}$ in the alternative fuel cycle. Because this isotope emits large amounts of gamma radiation, remote handling techniques are required. Another deterrent is the denaturing of the fissionable isotopes used to power the reactors. For instance, ${ }^{25} \mathrm{U}$ or ${ }^{256} \mathrm{U}$, the fissionable isotopes used in the alternative fuel cycle, must be essentially free of impurities (other nonfissioning uranium isotopes) to sustain a chain reaction. Denaturing is accomplished when a certain amount of the ${ }^{28} \mathrm{U}$ isotope is mixed with either ${ }^{233} U$ or ${ }^{280} \mathrm{U}$. Complex and/or expensive isotope separation methods are required to obtain the fissionable isotopes.
The alternative fuels have a lower breeding ratio ${ }^{1}$ and longer doubling time $\mathrm{e}^{2}$ than the $(\mathrm{U}, \mathrm{Pu}) \mathrm{C}$ fuel. Because the (Th, U)C fuel has a higher melting temperature than the $(\mathrm{U}, \mathrm{Pu}) \mathrm{C}$ fuel, the thoriumbased fuel system can operate at higher temperatures, thus possibly offsetting the lower thermal conductivity of the thorium-based system. A comparison of their oxide analogs shows that the (Th, U)C and (Th, Pu)C fuels have higher metal density, thermal conductivity, and breeding ratio properties.

The Los Alamos Scientific Laboratory (LASL) initiated these fabrication studies in an effort to establish a fabrication process for alternative fuels using the carbothermic reduction process. By using this process we can prepare kilogram quantities of fuel with good reproducibility of chemical and phase composition. Other fabrication methods use liquid techniques, which form carbide microspheres, and alloying techniques, which form thorium-uranium or thorium-plutonium alloys. With the liquid methods one cannot process large quantities of fuel because of criticality concerns, and with the alloying methods one cannot control the process conditions. 


\section{FUEL COMPOSITION AND FABRICA- TION PROCESS}

\section{A. Fuel Composition}

We used the carbothermic reduction process to fabricate the alternative fuels as well as the $(\mathrm{U}, \mathrm{Pu}) \mathrm{C}$ fuel. In sodium-bonded fuel elements of the $(\mathrm{U}, \mathrm{Pu}) \mathrm{C}$ system, carburization of the cladding is enhanced when the carbon-to-metal atom ratio in the fuel is greater than unity. However, if the fuel being prepared has a carbon-to-metal atom ratio much less than unity, the chance of producing free metal during burnup is high. The metal settles in the grain boundaries of the fuel and increases the fuel swelling rate. It also interacts with the cladding, causing lowmelting eutectics. Therefore, one can prepare (Th, U) $\mathrm{C}$ and ( $\mathrm{Th}, \mathrm{Pu}$ ) C fuels whose carbon-to-metal atom ratios are equal to or slightly less than unity. This is confirmed by comparing the phase diagrams of the thorium-carbon, plutonium-carbon, and uranium-carbon systems.

The phase diagram of the thorium-carbon system ${ }^{3}$ (Fig. 1) shows that thorium-monocarbide exists in the carbon-to-thorium atom ratio range of 0.675 to 1.0. With this broad compositional range and high melting point of $2600^{\circ} \mathrm{C}$, one essentially eliminates the concern of obtaining the dicarbide phase or free metal.

The phase diagram of the uranium-carbon system* (Fig. 2) indicates the difficulty in obtaining uranium-monocarbide. The carbon-to-uranium atom ratio for the single-phase material narrows to unity at temperatures below $800^{\circ} \mathrm{C}$. An atom ratio

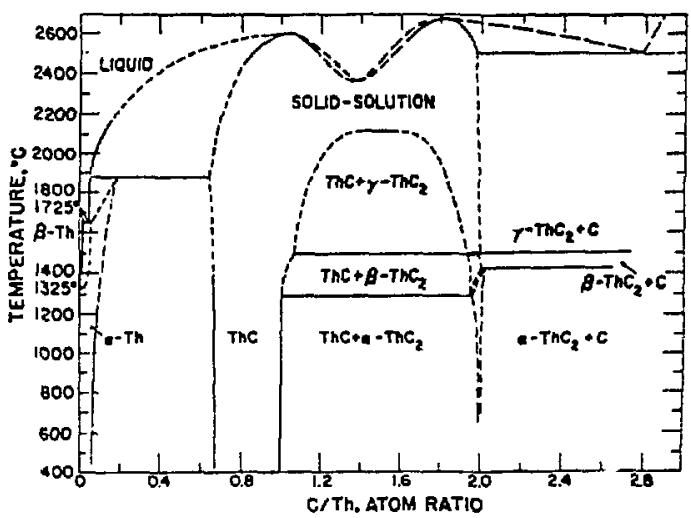

Fig. 1.

Phase diagram of the thorium-carbon system.

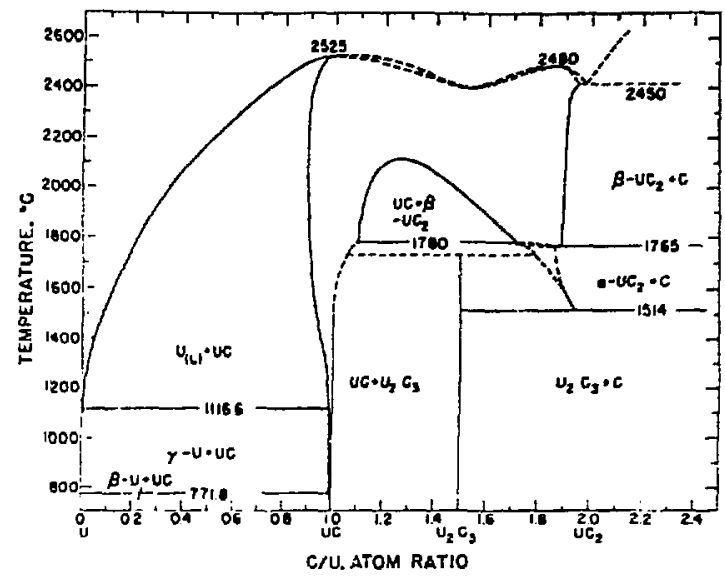

Fig. 2.

Phase diagram of the uranium-carbon system.

greater than unity produces some higher carbide phases and a ratio less than unity produces some free metal.

In the plutonium-carbon system ${ }^{6}$ (Fig. 3) the carbon-to-plutonium atom ratio range for plutonium-monocarbide is 0.8 to 0.9 . This range is not as broad as for thorium-monocarbide, and the melting point for the solid-solution plutonium. monocarbide occurs at $1600^{\circ} \mathrm{C}$.

On the hasis of the phase diagrams, we prepared the three (Th, U)C fuel compositions listed in Table i with carbon-to-metal atom ratios of 0.90 and 0.95 . The metal is an $80 / 20$ mixture of thorium/uranium. For the two (Th,Pu)C fuel compositions, we used a

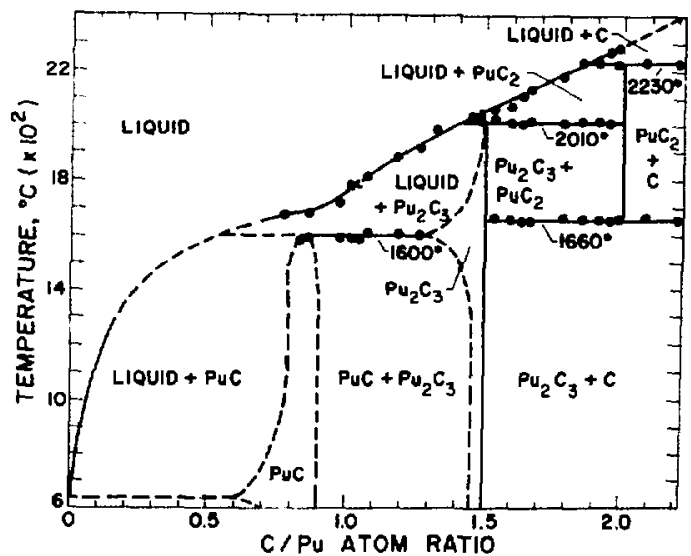

Fig. 3.

Phase diagram of the plutonium-carbon system. 


\section{TABLE I}

\section{FUEL COMPOSITIONS}

\section{Thorium-Uranium Carbide}

$$
\begin{aligned}
& \left(\mathrm{Th}_{0.8},{ }^{288} \mathrm{U}_{0.2}\right) \mathrm{C}_{0.80} \\
& \left(\mathrm{Th}_{0.8} \cdot{ }^{298} \mathrm{U}_{0.2}\right) \mathrm{C}_{0.95} \\
& \left(\mathrm{Th}_{0.8},{ }^{236} \mathrm{U}_{0.2}\right) \mathrm{C}_{0.95}
\end{aligned}
$$

\section{Thorium-Plutonium Carbide}

$$
\begin{aligned}
& \left.{ }^{\prime} \mathrm{l}^{\prime} \mathrm{h}_{0.8} \cdot \mathrm{Pu}_{0.2}\right) \mathrm{C}_{0.95} \\
& \left(\mathrm{Th}_{0.45} \cdot \mathrm{Pu}_{0.65}\right) \mathrm{C}_{0.85}
\end{aligned}
$$

carbon-to-metal atom ratio of 0.95 . The two compositions consist of an $80 / 20$ and a 45/55 mixture of thorium/plutonium. The latter composition is designed to obtain the proper linear power when used in the EBR-II reactor. The other compositions are designed for irradiation tests in the fast test reactor.

\section{B. Fabrication Process}

Figure 4 shows the fabrication process used for the alternative fuels. The first step involves the weighing. blending, and briquetting of the specified oxides and carbon. The batch was divided; half of the briquettes were vacuum-reduced at $1750^{\circ} \mathrm{C}$ and half were vacuum-reduced at $2000^{\circ} \mathrm{C}$. Each batch was then comminuted and sieved through a specified mesh screen. If high-density fuel was specified, nickel powder $(0.2 \mathrm{wt} \%)$ was added and blended into the carbide powder as a sintering aid. The material was then pressed into pellets using a Carver press. The low-density pellets were sintered at $1800^{\circ} \mathrm{C}$ for $8 \mathrm{~h}$ and the high-density pellets were sintered at $2000^{\circ} \mathrm{C}$ for $2 \mathrm{~h}$.

\section{RESULTS}

\section{A. (Th,U)C Fuel and ThC Insulator Pellets}

Table II lists the weight percent of carbon and oxygen for the various (Th, U)C fuels and ThC in- sulator pellets. The first (Th, $\mathrm{W})(\mathrm{composition}(94 \%$ TD) prepared had a carbon-to-metal atom ratio of 0.90 . A comparison of the weight percent carbon and oxygen of the briquettes from the vacuum-reduction cycles of $1750^{\circ} \mathrm{C}$ and $2000^{\circ} \mathrm{C}$ shows an incomplete reaction of the material from the $1750^{\circ} \mathrm{C}$ reduction. This is evident by the larger amount of carbon and oxygen in the briquettes reduced at $1750^{\circ} \mathrm{C}$. When the material from both reduction cycles is comminuted, pressed, and sintered at $2000^{\circ} \mathrm{C}$, the carbon and oxygen content of the pellets from buth reduction cycles is nearly equivalent. The material incompletely reduced at $1750^{\circ} \mathrm{C}$ and sintered at $2000^{\circ} \mathrm{C}$ is able to progress to the same reaction stage as the material reduced and sintered at $2000^{\circ} \mathrm{C}$. The microstructure of the $\left(\mathrm{Th}_{0.8}{ }^{238} \mathrm{U}_{0.2}\right) \mathrm{C}_{0.80}$ pellets indicates a second phase that we believe to be oxycarbide. Previous studies indicate that oxycarbide can be minimized by having a carbon-to-metal ratio of unity.

We prepared a batch of (Th.U)C fuel with a carbon-to-metal ratio of 0.95 . When vacuumreduced at $1750^{\circ} \mathrm{C}$, the briquettes of the $\left(\mathrm{Th}_{0.8}{ }^{298} \mathrm{U}_{0.2 .}\right) \mathrm{C}_{0.85}$ composition (95\% TD) contain less carbon and oxygen than those of the $\left(\mathrm{Th}_{0.8},{ }^{280} \mathrm{U}_{0.2}\right) \mathrm{C}_{0.80}$ composition. However, when vacuum-reduced at $2000^{\circ} \mathrm{C}$, both compositions show very little difference in carbon and oxygen content.

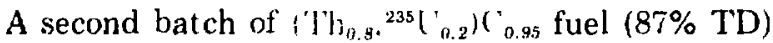
was prepared using a reduction temperature of $20000^{\circ} \mathrm{C}$ and a sintering temperature of $18000^{\circ} \mathrm{C}$. The fuel sintered at $18(4)^{\circ}\left({ }^{\circ}\right.$ (ontains more oxygen than the same composition sintered at $20000^{\circ} \mathrm{C}$.

We prepared a barch of Th $\mathrm{C}$ insulator pellets with a carbon-to-metal ratio si 0.90 using the $1750^{\circ} \mathrm{C}$ and $2000^{\circ} \mathrm{C}$ vacuum-reduction cycles. This material did not behave like the (Th, () $\mathrm{C}$ fuel; that is, the material reduced at $1750^{\circ} \mathrm{C}$ and sintered at $2000^{\circ} \mathrm{C}$ did not progress to the same reaction stage as that reduced and sintered at $2000^{\circ} \mathrm{C}$.

Thorium carbides attract oxygen and water. ${ }^{\circ}$ The sintered pellets from the $1750^{\circ} \mathrm{C}$ and $2000^{\circ} \mathrm{C}$ reduction cycles show a higher oxygen content than the briquettes. The oxygen probably is acquired during the comminution step, when the material has a large surface area, even though a maximum concentration of $10 \mathrm{ppm}$ each for moisture and oxygen is maintained in the argon atmosphere of the glovebox. $\mathbf{O x}$ ygen contamination also may occur when the pellet is sampled for chemical analyses. 


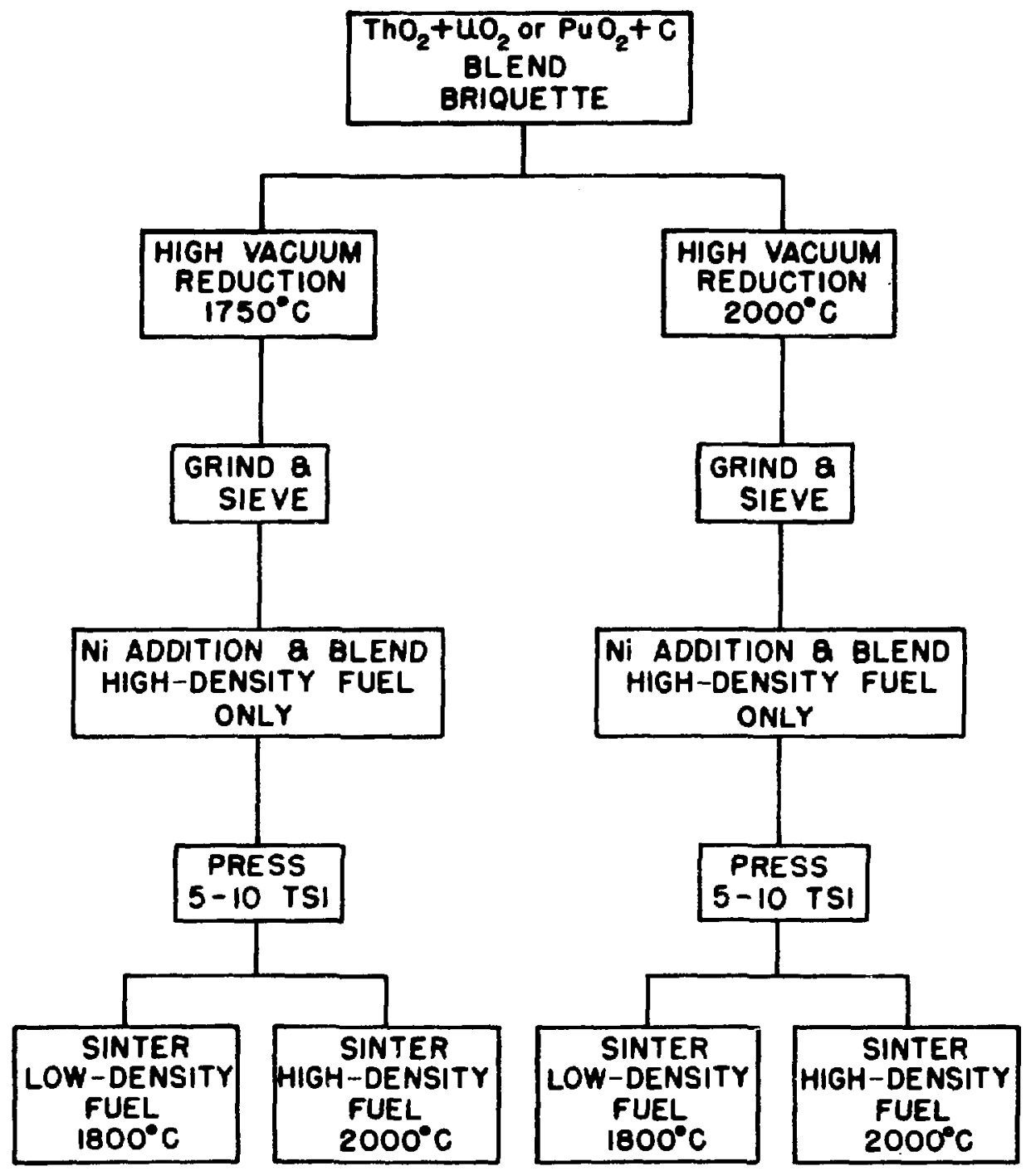

Fig. 4.

Fabrication process.

\section{B. (Th,Pu)C Fuel}

The chemical and physical data are listed in Table III for the (Th,Pu)C fuel with a carbon-tometal atom ratio of 0.95 . A batch of $\left(\mathrm{Th}_{0.8}, \mathrm{Pu}_{0.2}\right) \mathrm{C}_{0.06}$ fuel was charged and split in half for the two carboreduction cycles. The portion vacuum-reduced at $1750^{\circ} \mathrm{C}$ had $2.5 \%$ oxygen in the briquette and $2.3 \%$ in the sintered pellet. The remaining portion, vacuum-reduced at $2000^{\circ} \mathrm{C}$, had $0.54 \%$ oxygen in the briquette and $0.63 \%$ in the sintered pellet. Because of the high oxygen content in the material reduced at $1750^{\circ} \mathrm{C}$, a second batch of $\left(T h_{0.8} \mathrm{Pu}_{0.8}\right) \mathrm{C}_{0.98}$ fuel was prepared using only the $2000^{\circ} \mathrm{C}$ reduction cycle. Some pellets were sintered in flowing argon gas and the rest were sintered in a vacuum. Table III shows that for the two batches reduced at $2000^{\circ} \mathrm{C}$, the pellets sintered in a vacuum had a much lower carbon and oxygen content than those sintered in flowing argon gas. The results indicate that vacuum sintering reduces the amount of oxygen and carbon in the fuel.

We prepared two batches of $\left(\mathrm{Th}_{0.48}, \mathrm{Pu}_{0.00}\right) \mathrm{C}_{0 .}$ fuel. This composition, consisting of a $45 / 55$ mixture of thorium/plutonium, is representative of that required to provide the proper power density for the 


\section{TABLE II}

WEIGHT PERCENT OF CARBON AND OXYGEN FOR VARIOUS

(Th,U)C FUELS AND ThC INSULATOR PELLETS

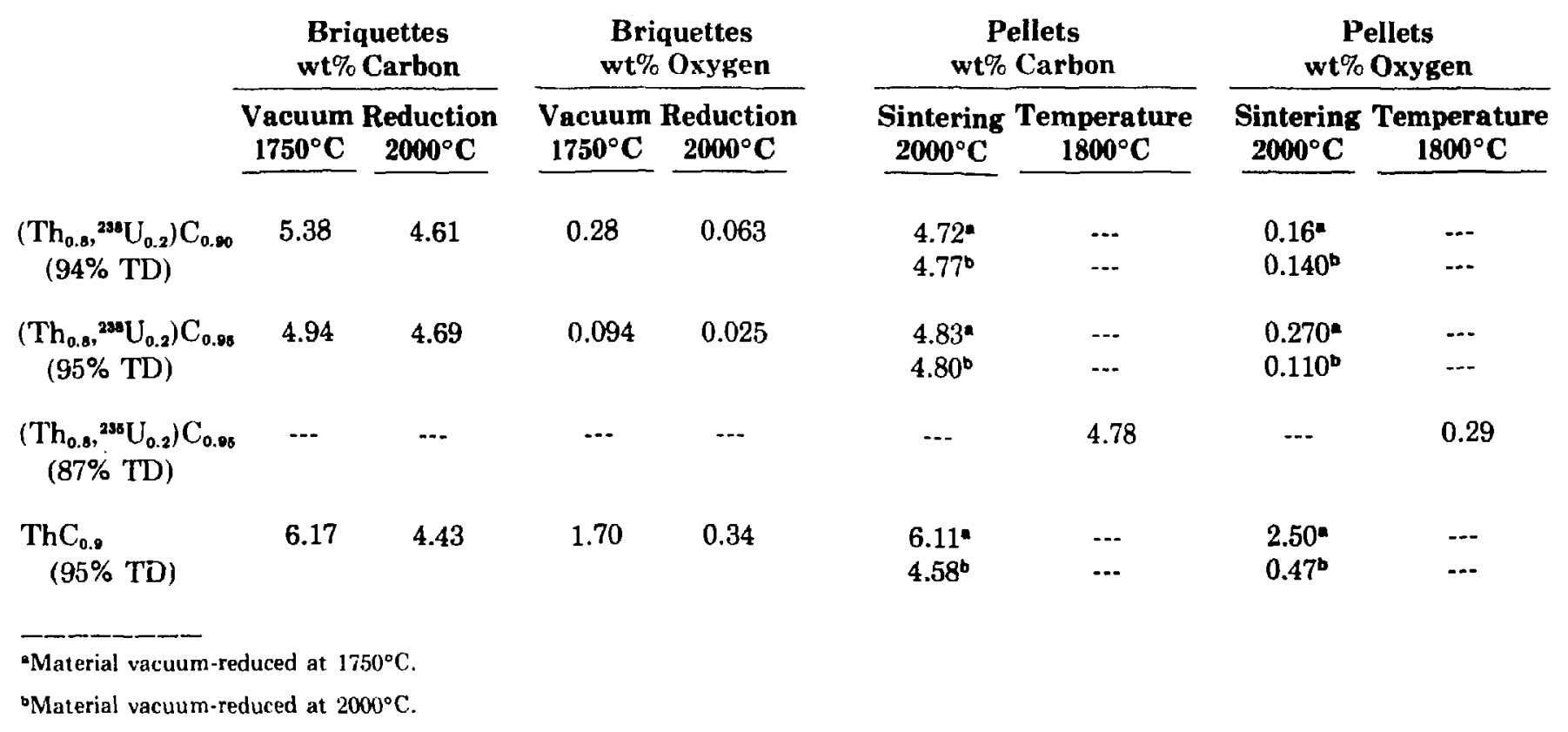


TABLE III

CHEMICAL AND PHYSICAL DATA FOR VARIOUS (Th,Pu)C FUELS

\begin{tabular}{|c|c|c|c|c|c|}
\hline & & $\begin{array}{c}\left(\mathrm{Th}_{0 . .6}, \mathbf{P u}_{0.2}\right) \mathrm{C}_{0.08} \\
\quad 87 \% \mathrm{TD}\end{array}$ & $\begin{array}{c}\left(\mathrm{Th}_{0.8}, \mathbf{P u}_{0.2}\right) \mathbf{C}_{0.88} \\
87 \% \mathrm{TD}\end{array}$ & $\begin{array}{c}\left(\mathbf{T h}_{\mathbf{0 . 4 8}}, \mathrm{Pu}_{\mathrm{0.s8}}\right) \mathbf{C}_{\mathbf{0 . 8 5}} \\
93 \% \mathrm{TD}\end{array}$ & $\begin{array}{c}\left(\mathrm{Th}_{0.45}, \mathrm{Pu}_{0.55}\right) \mathrm{C}_{0.95} \\
\text { Partial Melt }\end{array}$ \\
\hline Pellet & $\left.\mathrm{Ar}^{*}-1800^{\circ} \mathrm{C}\right)$, wt $\%$ carbon & 5.21 & 5.21 & 5.72 & $\cdots$ \\
\hline Pellet & $\left.\mathrm{V}^{\mathrm{b}}-1800^{\circ} \mathrm{C}\right)$, wt $\%$ carbon & --- & 4.94 & ... & $-\cdot$ \\
\hline Pellet & AR-1800), wt \% oxygen & 0.63 & 0.57 & 1.3 & ... \\
\hline Pellet & V-1800), wt \% oxygen & --- & 0.36 & $\cdots$ & $\cdots$ \\
\hline Initial & $\frac{\mathrm{Pu}}{\mathrm{Th}+\mathrm{Pu}}$ & 0.2082 & 0.2080 & 0.5653 & 0.5673 \\
\hline Final & $\frac{\mathrm{Pu}}{\mathrm{Th}+\mathrm{Pu}}$ & 0.1912 & 0.1927 & 0.5496 & 0.5209 \\
\hline Pluton & ium loss, wt $\%$ & 8.1 & 7.4 & 2.8 & 8.2 \\
\hline Vacuu & n Reduction, ${ }^{\circ} \mathrm{C}$ & 2000 & 2000 & 1750 & 2000 \\
\hline $\mathrm{C} / \mathrm{M}$ a & om ratio & $1.08(\mathrm{Ar})$ & $\begin{array}{l}1.08(\mathrm{Ar}) \\
1.03(\mathrm{~V})\end{array}$ & 1.21 (Ar) & $\cdots$ \\
\hline
\end{tabular}

Ar = sintered in flowing argon

$\checkmark v=$ sintered in vacuum. 
EBR-II reactor. The batch reduced at $1750^{\circ} \mathrm{C}$ shows a high carbon and oxygen content and an incomplete carbothermic reaction, which indicates the need to vacuum-reduce at a higher temperature. We used the thorium-carbon and plutonium-carbon phase diagrams to approximate a $2050^{\circ} \mathrm{C}$ melting point for this fuel. The briquettes from a batch of $\left(\mathrm{Th}_{0.48}, \mathrm{Pu}_{0.88}\right) \mathrm{C}_{0.88}$ reduced at $2000^{\circ} \mathrm{C}$ showed evidence of partial melting. The $32 \mathrm{wt} \%$ loss of material, compared with a $19 \mathrm{wt} \%$ loss for a typical carbothermic reduction, indicates that the material was close to $u^{*}$ on a solid-liquid phase boundary. As a result of this partial melt condition, the material was not processed beyond the vacuum-reduction stage. Note that the plutonium vaporization ranges between 7.4 and $8.1 \mathrm{wt} \%$ for the $\left(\mathrm{Th}_{0.8}, \mathrm{Pu}_{0.2}\right) \mathrm{C}_{0.08}$ composition vacuum-reduced at $2000^{\circ} \mathrm{C}$, whereas for the $\left(\mathrm{Th}_{0.46}, \mathrm{Pu}_{0.86}\right) \mathrm{C}_{0.08}$ composition vacuum-reduced at $1750^{\circ} \mathrm{C}$ it is $2.8 \mathrm{wt} \%$.

\section{Carbothermic Reduction-Gas Pressure vs Time}

As each batch of material was vacuum-reduced, the gas pressure of the products was recorded during the entire cycle. In Fig. 5 , the curves for the $1750^{\circ} \mathrm{C}$ and $2000^{\circ} \mathrm{C}$ cycles are nearly identical except for the last $3 \mathrm{~h}$ of vacuum reduction. During this 3 -h period, the oxycarbide decomposes and the excess oxygen

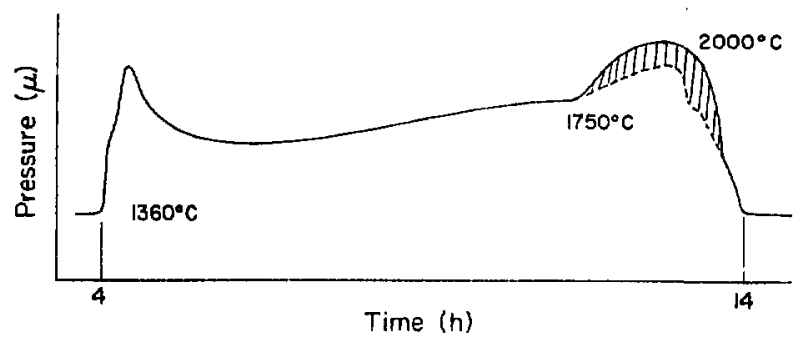

Fig. 5.

Carbothermic reduction showing gas pressure us time. Temperature was increased 1 degree per minute. comes off as carbon monoxide. The area between the two curves represents the difference in the progress of the carbothermic reduction of a material vacuumreduced at $1750^{\circ} \mathrm{C}$ and $2000^{\circ} \mathrm{C}$. The curves correlate with the chemical data. The material vacuumreduced at $2000^{\circ} \mathrm{C}$ has a lower oxygen and carbon content than that vacuum-reduced at $1750^{\circ} \mathrm{C}$.

\section{CONCLUSIONS}

The (Th, U)C and (Th, Pu)C fuels must maintain reaction temperatures above $1750^{\circ} \mathrm{C}$ to keep the oxygen content of the fuel at a minimum. On the basis of our examination of the chemical data and our initial microstructure studies, we believe that part of the oxygen is in the form of an oxycarbide phase. Also, we observed that vacuum sintering reduces the carbon and oxygen content in the fuel, as compared to identical material sintered in flowing argon gas. Finally, the thorium-plutonium carbides vaporize a large amount of plutonium when vacuum-reduced and sintered at temperatures above $1750^{\circ} \mathrm{C}$. If reaction temperatures are decreased to or below $1750^{\circ} \mathrm{C}$ to minimize plutonium vaporization, the oxygen content in the fuel remains high. However, this is not the case with $(\mathrm{U}, \mathrm{Pu}) \mathrm{C}$ fuel. A vacuum-reduction temperature of $1550^{\circ} \mathrm{C}$ is used to prepare the $(\mathrm{U}, \mathrm{Pu}) \mathrm{C}$ fuel, in which the plutonium vaporization is less by about a factor of 5 and the oxygen concentration is less than $300 \mathrm{ppm}$.

We doubt that the $\left(\mathrm{Th}_{0.48}, \mathrm{Pu}_{0.8 s}\right) \mathrm{C}_{0.08}$ fuel can be prepared using the carbothermic reduction process without the fuel containing a large amount of dissolved oxygen.

\section{REFERENCES}

1. D. Okrent, "Neutron Physics Considerations in Large Fast Reactors," Power React. Technol,, Vol. 7, No. 2, (Spring 1964).

2. P. R. Kasten, F. J. Homan, and E. J. Allen, "Assessment of the Thorium Fuel Cycle in Power Reactors," Oak Ridge National Laboratory report ORNL/TM-5565 (January 1977). 
3. E. K. Storms, The Refractory Carbides (Academic Press Inc., New York, 1967), Vol. 2, p. 158.

4. E. K. Storms, The Refractory Carbides (Academic Press Inc., New York, 1967), Vol. 2, p. 176 .
5. J. G. Reavis and 1. Reese, "Advanced Plutonium Fuels Program," Los Alamos Scientific Laboratsry report LA-4494-MS (August 1970), pp. 26-29.

6. E. K. Storms, The Refractory Crrbides (Academic Press Inc., New York, 1967), Vol. 2. p. 225 . 